\title{
A Map of Racial and Ethnic Disparities in Influenza Vaccine Uptake in the Medicare Fee-for-Service Program
}

\author{
Laura L. Hall · Liou Xu · Salaheddin M. Mahmud - Gary A. Puckrein • \\ Ed W. Thommes $\cdot$ Ayman Chit
}

Received: February 26, 2020 / Published online: April 9, 2020

(C) The Author(s) 2020

\section{ABSTRACT}

Introduction: Despite improved understanding of the risks of influenza and better vaccines for older patients, influenza vaccination rates remain subpar, including in high-risk groups such as older adults, and demonstrate significant racial and ethnic disparities.

Methods: This study considers demographic, clinical, and geographic correlates of influenza vaccination among Medicare Fee-for-Service (FFS) beneficiaries in 2015-2016 and maps the data on a geographic information system (GIS) at the zip code level.

Results: Analyses confirm that only half of the senior beneficiaries evidenced a claim for receiving an inactivated influenza vaccine (IIV),

Digital Features To view digital features for this article go to https://doi.org/10.6084/m9.figshare.12030666.

Electronic supplementary material The online version of this article (https://doi.org/10.1007/s12325020-01324-y) contains supplementary material, which is available to authorized users.

L. L. Hall $(\bowtie) \cdot$ L. Xu · G. A. Puckrein

National Minority Quality Forum, Washington, DC,

USA

e-mail: 1lhall@nmqf.org

S. M. Mahmud

University of Manitoba, Winnipeg, Canada

E. W. Thommes - A. Chit

Sanofi Pasteur, Swiftwater, PA, USA with significant disparities observed among black, Hispanic, rural, and poorer beneficiaries. More extensive disparities were observed for the high-dose (HD) vaccine, with its added protection for older populations and confirmed economic benefit. Most white beneficiaries received HD; no non-white subgroup did so. Mapping of the data confirmed subpar vaccination in vulnerable populations with wide variations at the zip code level.

Conclusion: Urgent and targeted efforts are needed to equitably increase IIV rates, thus protecting the most vulnerable populations from the negative health impact of influenza as well as the tax-paying public from the Medicare costs from failing to do so.

Keywords: Disparities; Geomapping; Infectious diseases; Influenza vaccine; Medicare 


\section{Key Summary Points}

Why carry out this study?

Despite improved understanding of the risks of influenza and better vaccines for older patients, influenza vaccination rates remain subpar, including in high-risk groups such as older adults, and demonstrate significant racial and ethnic disparities.

The study considers demographic, clinical, and geographic correlates of influenza vaccination among Medicare Fee-forService beneficiaries in the 2015-2016 flu season.

\section{What was learned from the study?}

Non-white beneficiaries, people dwelling in rural communities, and economically disadvantaged individuals are significantly less likely to receive a flu vaccine, especially a newer, more effective formula for older adults.

Vaccination rates vary geographically as well.

More frequent ambulatory care visits and prescriptions correlate with higher rates of vaccination.

Geographically and demographically targeted efforts may be required to better protect vulnerable older adults from influenza.

Ambulatory providers are potential resources for increasing flu vaccination.

Further analyses are required to understand these correlates of flu vaccination.

\section{INTRODUCTION}

Adults 65 years and older (here referred to as seniors) comprise the largest US population age group, with $>50$ million individuals. Moreover, 65 year olds today have an average life expectancy of 20 more years. Blacks, Hispanics, and other racial and ethnic subgroups are a growing part of this age cohort, currently constituting > $20 \%$ [1].

This large and growing population, with increasing health risks, contributes to rising health care costs, which are estimated at $17.9 \%$ of the gross domestic product or $\$ 3.5$ trillion, more than $\$ 1$ trillion of which is for the Medicare program, according to CMS estimates [2].

Among their health vulnerabilities, older adults are at increased risk of influenza infection, reflecting the decline in immune system functioning with age $[3,4]$. Older adults face the most serious consequences of influenza, with the highest hospitalization rates, exacerbated chronic illness such as diabetes and heart disease, and increased frailty and disability, which often threaten independence-approximately $15 \%$ of older people admitted to the hospital with influenza lose two or more basic self-care functions $[5,6]$. Older adults are much more likely to die from the disease than any other age group as well: Ninety percent of the $>$ 80,000 Americans who died from influenza in 2017-2018 were 65 years of age or older [7].

Immunosenescence also renders older adults less responsive to the standard influenza vaccine (SD) $[4,8]$. Fortunately, newer formulations afford heightened protection for older adults with declining immune system responsiveness [9]. The most studied such option, the high-dose inactivated trivalent influenza vaccine (HD), has been shown in large randomized controlled trials and meta-analyses to be more efficacious over SD in preventing laboratoryconfirmed influenza, hospital admissions, and mortality [10-14]. Recent data suggest health care costs savings as well [15].

Despite growing risks and more effective vaccines, inactivated influenza vaccination (IIV) coverage falls short of the Healthy People 2020 goal of $90 \%$ coverage among seniors, with persisting racial and ethnic disparities. While IIV increased $8.2 \%$ in the 2018-2019 versus 2017-2018 season, coverage among adults $\geq 18$ years was estimated at $45.3 \%$, with $68 \%$ of adults $\geq 65$ years vaccinated. In survey 
data [16], IIV coverage was higher in non-Hispanic whites than in all other ethnic and racial groups, with $48.7 \%$ of white only, non-Hispanic adults receiving the vaccine, significantly higher than $39.4 \%, 37.1 \%$, and $37.6 \%$ in blacks, Hispanics, and American Indians/Alaska Natives, respectively. Study of Medicare trends shows significant racial and ethnic disparities among beneficiaries with a chronic condition, a population at increased risk of hospitalization and death [17]. Previous analysis of Medical Current Beneficiary Survey (MCBS) data and mortality rates led to the conclusion that racial "[p]arity in vaccination beginning at age 65 and continuing through out life would save more than 33,000 minority years of life" [18]. Equity in influenza vaccination would prevent an estimated 1330 black and 550 Hispanic deaths each year; attaining the Healthy People 2020's target goal would spare an estimated 3750 lives. The prevention of illness and death would translate into cost savings as well: excess hospitalizations, estimated at nearly one-half million blacks versus whites, contribute significantly to the economic burden on the US healthcare system, with its estimated cost of $>$ 30 billion dollars annually.

The purpose of this study was to analyze and map IIV coverage among seniors in the Medicare Fee-for-Service (FFS) program to assess demographic, clinical, and geographic disparities. Characteristics of the beneficiaries for whom an IIV claim (SD or HD) was documented (immunization status) were compared with the population without a record of IIV reimbursement and the association between immunization status and various social and clinical characteristics, including age, race/ethnicity, income, healthcare utilization behavior, chronic health status, and geographic location, were determined. In addition, the immunization status of Medicare FFS beneficiaries is displayed on a GIS (geographic information system) providing visual information about the geographic distribution of vaccination by demographic, clinical, and cost factors [19]. The results inform a roadmap for future research and advocacy promoting vaccination and equity in the Medicare program.

\section{METHODS}

The main objective of this study was to characterize the uptake pattern of IIV, including HD or SD, among seniors in Medicare FFS by demographic, clinical, and healthcare characteristics for the 2015-2016 influenza season. The second objective was to geographically display vaccine rates at the zip code level. This article does not contain any new studies with human or animal subjects performed by any of the authors. The data analyses did not include any patient identifiers, and the aggregated data never included $<11$ patient records as required by NMQF's Data Use Agreement with the Center for Medicare and Medicaid Services as a HIPPA compliant study with a waiver of IRB approval.

\section{Data Sources}

Source data included the CMS 2015-2016 Carrier File, Master Beneficiary Summary File (MBSF), and Outpatient File for Medicare FFS beneficiaries $\geq 65$ years of age who received an influenza vaccine. Patient-level data included: age group, gender, race and ethnicity, chronic condition, number of ambulatory visits, number of hospitalizations, number of prescriptions, reimbursement for a pneumonia shot, receipt of the full or partial Part D low-income subsidy over the 2015-2016 influenza season, and geographic unit (including zip code, county, state, and region), with no fewer than 11 beneficiaries per cell. The influenza vaccine season used to search for influenza immunization status was defined as 1 July 2015 through 30 June 2016.

The MBSF is compiled annually and includes demographics (e.g., date of birth/death, gender, race and ethnicity), enrollment status (e.g., number of months enrolled in Part A, B, and C), and status of common chronic conditions for all beneficiaries who were enrolled in the Medicare program for any part of the year [20]. The MBSF also contains a unique beneficiary identification number, permitting linkage of the data to the Medicare Carrier and Outpatient Files, which provides information on care in the ambulatory and hospital outpatient settings, 
respectively. The claims data from the Carrier and Outpatient Files were used to identify beneficiaries' influenza vaccine status during the 2015-2016 season with a CPT code for an influenza vaccine (Appendix A). Subsequent records of IIV vaccination were ignored.

\section{Data Analysis}

A cohort of FFS beneficiaries was defined by excluding beneficiaries who did not have Part A or B FFS coverage at the initiation of the study period, or had such coverage but for < 3 months, or were admitted to a long-term care facility. Percentage of Medicare FFS beneficiaries vaccinated was calculated overall and by sociodemographic and clinical characteristics. All analyses were conducted with SAS version 9.4 .

\section{Geographic Information System and Data Visualization}

Data were uploaded to a visualization platform developed using open source software and a relational database, allowing users to view population heat maps based on a variety of characteristics such as a vaccine type, chronic condition, demographics, and clinical services utilization and costs.

\section{RESULTS}

\section{Beneficiary Demographic Characteristics and Influenza Immunization Status}

Most beneficiaries were between the ages of 65 and 70 years $(8,670,811$ or $32.8 \%)$, with between 4.6 and 6.7 million included in the other age categories (Table 1). Forty-seven percent of the study cohort had a reimbursement

Table 1 Influenza immunization by beneficiary demographic characteristics

\begin{tabular}{lllll}
\hline & Total study cohort $(\boldsymbol{N})$ & Total vaccinated \% $(\boldsymbol{N})$ & HD \% $(\boldsymbol{N})$ & SD \% $(\boldsymbol{N})$ \\
\hline Overall & $26,466,244$ & $47.4 \%(12,557,232)$ & $25.0 \%(6,613,247)$ & $22.4 \%(5,943,985)$ \\
Age group & & & & \\
$65 \leq$ age $<70$ & $8,670,811$ & $39.9 \%(3,462,763)$ & $21.0 \%(1,824,957)$ & $18.9 \%(1,637,806)$ \\
$70 \leq$ age $<75$ & $6,391,918$ & $48.3 \%(3,087,771)$ & $26.5 \%(1,693,712)$ & $21.8 \%(1,394,059)$ \\
$75 \leq$ age $<80$ & $4,646,357$ & $52.3 \%(2,428,234)$ & $28.2 \%(1,309,946)$ & $24.1 \%(1,118,288)$ \\
Age $\geq 80$ & $6,757,158$ & $53.0 \%(3,578,464)$ & $26.4 \%(1,784,632)$ & $26.5 \%(1,793,832)$ \\
Gender & & & & \\
Male & $11,631,495$ & $44.8 \%(5,213,908)$ & $24.0 \%(2,788,594)$ & $20.9 \%(2,425,314)$ \\
Female & $14,834,747$ & $49.5 \%(7,343,323)$ & $25.8 \%(3,824,653)$ & $23.7 \%(3,518,670)$ \\
Race & & & & \\
White & $22,490,404$ & $49.4 \%(11,100,020)$ & $26.6 \%(5,988,474)$ & $22.7 \%(5,111,546)$ \\
Black & $2,054,934$ & $32.6 \%(670,797)$ & $13.4 \%(275,971)$ & $19.2 \%(394,826)$ \\
Asian & 535,452 & $47.6 \%(254,805)$ & $19.2 \%(103,058)$ & $28.3 \%(151,747)$ \\
Hispanic & 454,921 & $29.1 \%(132,170)$ & $11.0 \%(50,263)$ & $18.0 \%(81,907)$ \\
Other & 573,165 & $43.4 \%(248,506)$ & $19.6 \%(112,556)$ & $23.7 \%(135,950)$ \\
\hline
\end{tabular}


for an IIV, with most (25\%) receiving HD. Increasing age correlated with increased likelihood of receiving any IIV (39.9-53.0\%). HD exceeded SD in all age groups except the oldest, $\geq 80$ years. Female beneficiaries received more IIV than men (49.5\% versus $44.8 \%)$, including both SD (23.7\% versus $20.9 \%)$ and HD (25.8\% versus $24.0 \%$ ). The age and gender trends were similar across racial and ethnic groups and geographic regions, except for the race categories Black and Other and Region category Other where the rates of IIV uptake seem to be decreasing for age $\geq 80$ years.

Major differences in receiving any IIV, SD, or HD were observed between beneficiaries from different racial and ethnic backgrounds. Nearly half of the White and Asian beneficiaries received an IIV (49.4\% and $47.6 \%$, respectively) compared with $32.6 \%$ and $29.1 \%$ of Blacks and Hispanics, respectively. All non-White subgroups received less HD: $26.6 \%$ of Whites received HD, while Asians, Blacks, and Hispanics received $19.2 \%, 13.4 \%$, and $11 \%$, respectively.

\section{Beneficiary Clinical Characteristics and Influenza Immunization}

Having one or more chronic condition was correlated with higher IIV percentages (Table 2). Only $32.9 \%$ of beneficiaries without a chronic condition had a record of IIV versus 53.5 to $54.8 \%$ of individuals with one or more such conditions. The uptake of HD was higher in the group of beneficiaries without a chronic condition, $19.3 \%$ versus $13.6 \%$, and HD uptake diminishing with increasing numbers of chronic conditions. HD uptake percentages ranged from $11.5 \%$ in beneficiaries with schizophrenia to $31 \%$ in beneficiaries with glaucoma.

\section{Beneficiary Service Utilization and Influenza Immunization}

While hospitalization or emergency department visits did not correlate with increased receipt of IIV, increasing numbers of physician visits and prescriptions did (Table 3). Fewer than two visits to a physician was linked to a $25.4 \%$ IIV uptake; ten or more visits was linked to a $62.7 \%$ uptake. Similarly, $36.0 \%$ of beneficiaries without a part D prescription received a IIV; $11-30$ prescriptions were linked to $56.5 \%$ uptake; 30 plus prescriptions revealed $56.7 \%$. Beneficiaries with any physician visits were more likely to receive HD than SD. The opposite is true of hospitalizations, with more hospitalizations correlated to more SD. Examination of IIV percentage by consumption group-population subsets based on total annual Medicare expenditures-did not reveal a clear trend. The Crisis Consumption group was the least likely to be vaccinated or to receive an HD (Table 4). Moderate and Light Consumption groups had the highest IIV and HD percentages.

Other care-related factors correlated with IIV and HD receipt. Beneficiaries who received full

Table 2 Immunization of beneficiaries with chronic condition

\begin{tabular}{|c|c|c|c|c|}
\hline & Total study cohort $(N)$ & Total vaccinated $\%(N)$ & HD \% $(N)$ & SD \% $(N)$ \\
\hline Had any chronic condition & $18,250,011$ & $54.0 \%(9,857,004)$ & $27.6 \%(5,030,020)$ & $26.4 \%(4,826,984)$ \\
\hline \multicolumn{5}{|l|}{ Number of chronic conditions } \\
\hline 0 & $8,216,233$ & $32.9 \%(2,700,228)$ & $19.3 \%(1,583,227)$ & $13.6 \%(1,117,001)$ \\
\hline 1 & $8,844,665$ & $53.5 \%(4,729,412)$ & $29.0 \%(2,567,578)$ & $24.4 \%(2,161,834)$ \\
\hline 2 & $5,932,987$ & $54.8 \%(3,253,338)$ & $27.4 \%(1,628,589)$ & $27.4 \%(1,624,749)$ \\
\hline $3+$ & $3,472,359$ & $54.0 \%(1,874,254)$ & $24.0 \%(833,853)$ & $30.0 \%(1,040,401)$ \\
\hline
\end{tabular}


Table 3 Beneficiary service utilization characteristics

\begin{tabular}{|c|c|c|c|c|}
\hline & Total study cohort $(N)$ & Total vaccinated $\%(N)$ & HD \% $(N)$ & SD \% $(N)$ \\
\hline \multicolumn{5}{|c|}{ Number of hospitalizations } \\
\hline 0 & $22,760,645$ & $47.3 \%(10,762,114)$ & $25.4 \%(5,770,179)$ & $21.9 \%(4,991,935)$ \\
\hline 1 & $2,562,198$ & $50.3 \%(1,288,416)$ & $24.4 \%(624,877)$ & $25.9 \%(663,539)$ \\
\hline $2+$ & $1,143,401$ & $44.3 \%(506,702)$ & $19.1 \%(218,191)$ & $25.2 \%(288,511)$ \\
\hline \multicolumn{5}{|c|}{ Number of outpatient ER visits } \\
\hline 0 & $20,768,473$ & $46.6 \%(9,676,596)$ & $25.0 \%(5,200,039)$ & $21.6 \%(4,476,557)$ \\
\hline 1 & $3,824,399$ & $51.3 \%(1,960,069)$ & $25.9 \%(989,390)$ & $25.4 \%(970,679)$ \\
\hline $2+$ & $1,873,372$ & $49.1 \%(920,567)$ & $22.6 \%(423,818)$ & $26.5 \%(496,749)$ \\
\hline \multicolumn{5}{|c|}{ Number of physician visits } \\
\hline$\leq 2$ & $7,821,959$ & $25.4 \%(1,983,977)$ & $13.4 \%(1,044,820)$ & $12.0 \%(939,157)$ \\
\hline $3-5$ & $5,701,368$ & $49.4 \%(2,815,407)$ & $27.0 \%(1,538,079)$ & $22.4 \%(1,277,328)$ \\
\hline $6-10$ & $6,495,851$ & $57.2 \%(3,715,403)$ & $30.6 \%(1,985,949)$ & $26.6 \%(1,729,454)$ \\
\hline$>10$ & $6,447,066$ & $62.7 \%(4,042,445)$ & $31.7 \%(2,044,399)$ & $31.0 \%(1,998,046)$ \\
\hline \multicolumn{5}{|c|}{ Number of Part D prescriptions } \\
\hline 0 & $10,022,110$ & $36.0 \%(3,607,843)$ & $19.0 \%(1,903,379)$ & $17.0 \%(1,704,464)$ \\
\hline $1-10$ & $2,927,459$ & $44.4 \%(1,299,968)$ & $25.7 \%(753,649)$ & $18.7 \%(546,319)$ \\
\hline $11-30$ & $6,373,719$ & $56.5 \%(3,602,608)$ & $31.7 \%(2,020,422)$ & $24.8 \%(1,582,186)$ \\
\hline$>30$ & $7,142,956$ & $56.7 \%(4,046,813)$ & $27.1 \%(1,935,797)$ & $29.6 \%(2,111,016)$ \\
\hline
\end{tabular}

Table 4 Consumption clusters and IIV uptake

\begin{tabular}{lclll}
\hline Consumption clusters & $\begin{array}{l}\text { Total study cohort } \\
(\boldsymbol{N})\end{array}$ & $\begin{array}{l}\text { Total vaccinated \% } \\
(\boldsymbol{N})\end{array}$ & HD \% $(\boldsymbol{N})$ & SD \% (N) \\
\hline Crisis (99th percentile) & 176,104 & $36.4 \%(64,145)$ & $27.6 \%(5,030,020)$ & $26.4 \%(4,826,984)$ \\
Heavy (90-98th percentile) & $1,892,168$ & $47.8 \%(904,916)$ & $19.3 \%(1,583,227)$ & $13.6 \%(1,117,001)$ \\
$\begin{array}{l}\text { Moderate (75-89th } \\
\text { percentile) }\end{array}$ & $3,727,310$ & $55.5 \%(2,069,866)$ & $29.0 \%(2,567,578)$ & $24.4 \%(2,161,834)$ \\
Light (50-49th percentile) & $6,446,762$ & $58.3 \%(3,757,489)$ & $27.4 \%(1,628,589)$ & $27.4 \%(1,624,749)$ \\
Low (1-49th percentile) & $14,223,900$ & $40.5 \%(5,760,816)$ & $22.3 \%(3,174,043)$ & $18.2 \%(2,586,773)$ \\
\hline
\end{tabular}

or partial Part D low-income subsidy had low rates of flu vaccination (38.5\%) and were nearly two times more likely to receive SD versus HD $(24.2 \%$ vs. $14.3 \%)$. In contrast, receipt of a pneumonia vaccine correlated to the highest rates of flu vaccination seen in the study$76.1 \%$-with increased likelihood of HD vs. SD (43.5\% vs. $32.6 \%)$. 


\section{Regional Variation in Influenza Immunization}

The percentage of beneficiaries immunized varied by US region as well as between rural and urban areas. The highest uptake of IIV occurred in the Northeast-50.8\%-and the lowest in the West-43.7\%-and Other regions (including Puerto Rico and other islands)-13.5\% (Table 5). HD vaccination is highest in the Midwest at $27.1 \%$, several percentage points above $\mathrm{SD}$, at $21.7 \%$.

Table 5 Regional variation in vaccination

\begin{tabular}{lclll}
\hline & Total study cohort $(\boldsymbol{N})$ & Total vaccinated \% $(\boldsymbol{N})$ & HD \% $(\boldsymbol{N})$ & SD \% $(\boldsymbol{N})$ \\
\hline Region & & & & \\
Northeast & $4,868,072$ & $50.8 \%(2,471,160)$ & $25.9 \%(1,260,686)$ & $24.9 \%(1,210,474)$ \\
Midwest & $5,923,190$ & $48.8 \%(2,891,825)$ & $27.1 \%(1,604,877)$ & $21.7 \%(1,286,948)$ \\
South & $10,438,678$ & $47.4 \%(4,943,052)$ & $24.5 \%(2,555,044)$ & $22.9 \%(2,388,008)$ \\
West & $5,112,420$ & $43.7 \%(2,234,476)$ & $23.2 \%(1,188,317)$ & $20.5 \%(1,046,159)$ \\
Other & 123,884 & $13.5 \%(16,719)$ & $3.5 \%(4,323)$ & $10.0 \%(12,396)$ \\
Rural/urban area & & & & \\
Urban & $20,714,927$ & $48.5 \%(10,045,128)$ & $26.4 \%(5,474,295)$ & $22.1 \%(4,570,833)$ \\
Rural & $5,751,317$ & $43.7 \%(2,512,104)$ & $19.8 \%(1,138,952)$ & $23.9 \%(1,373,152)$ \\
\hline
\end{tabular}

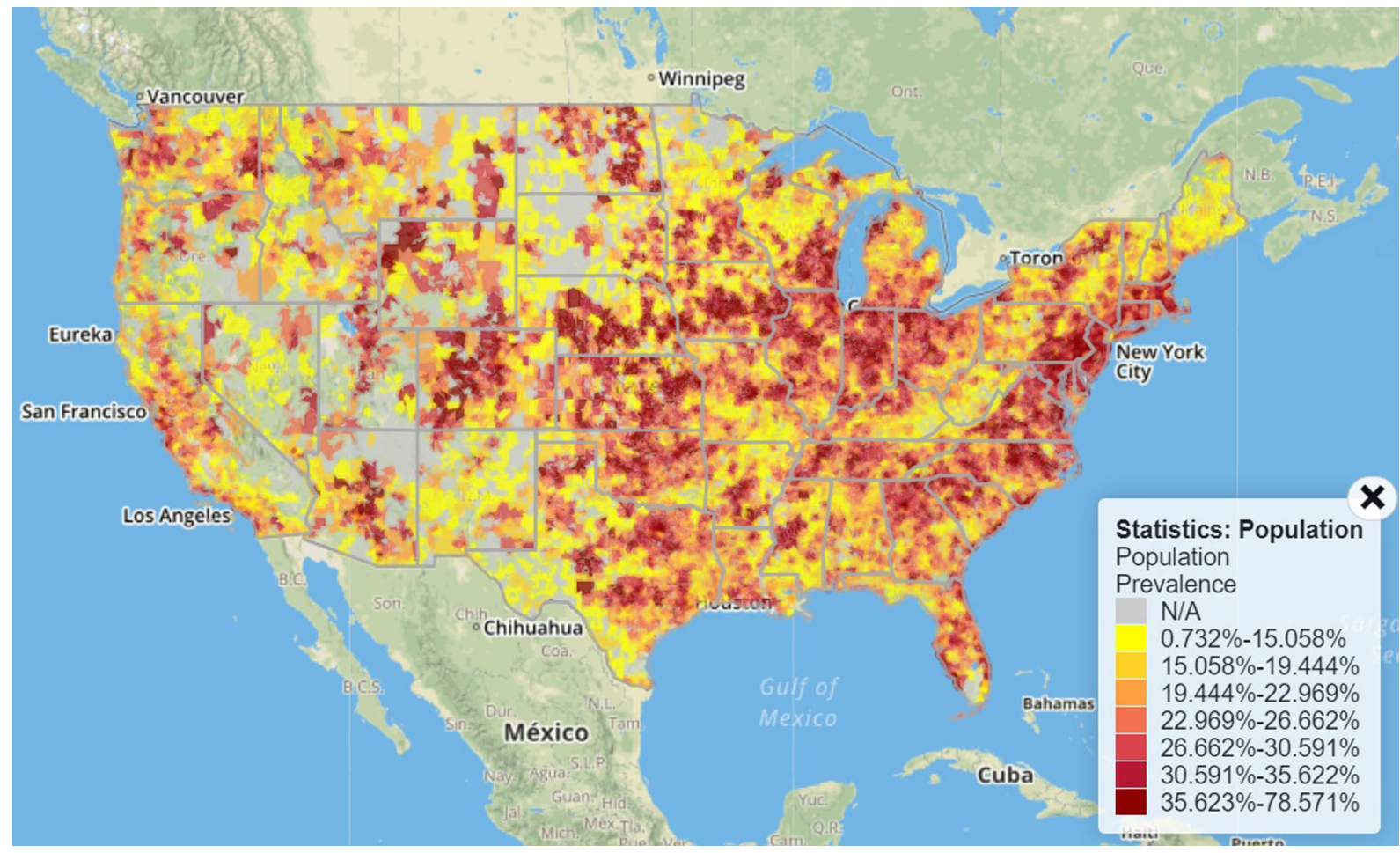

Fig. 1 IIV uptake mapped to the zip code level for white Medicare FFS beneficiaries 


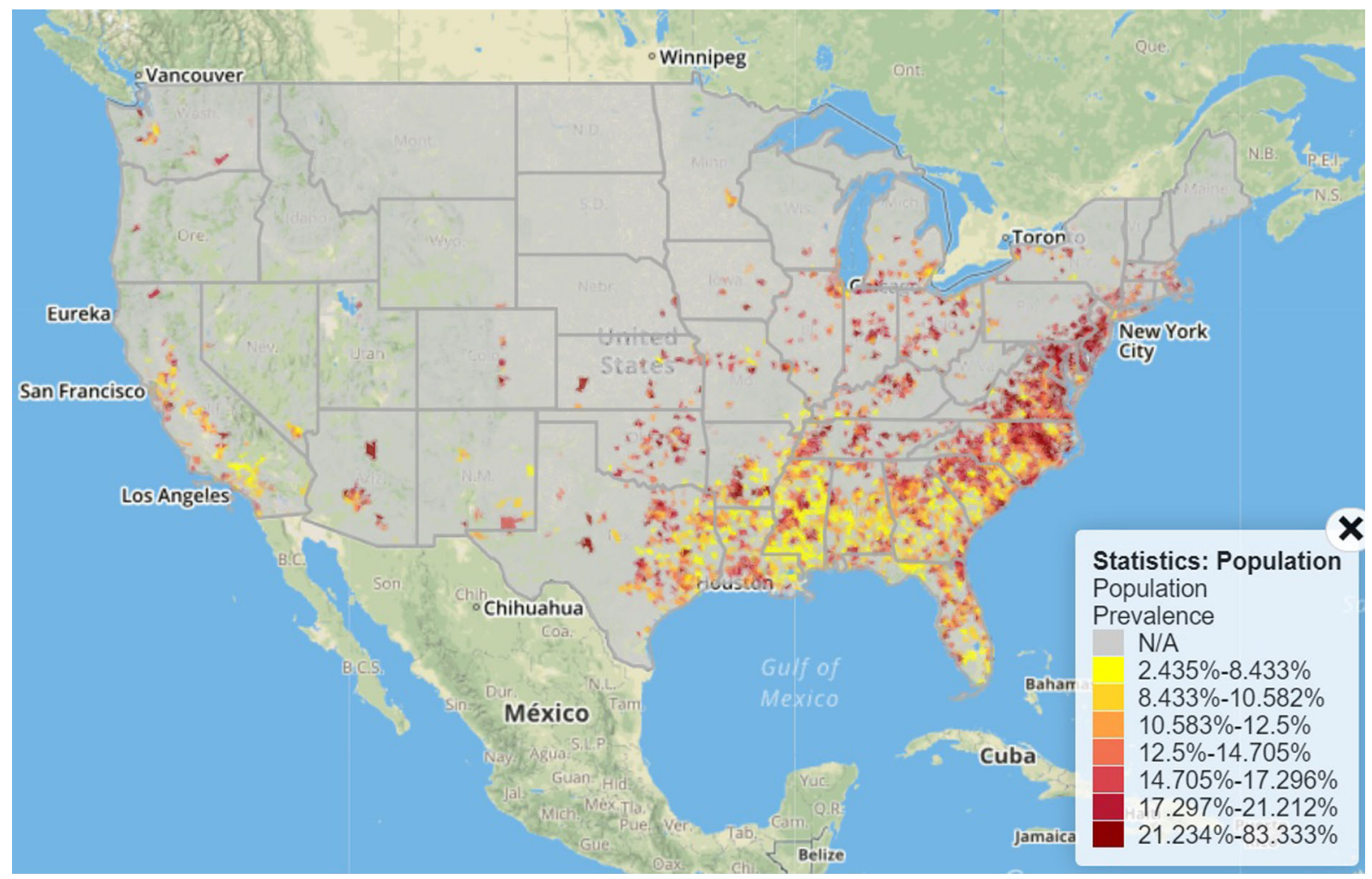

Fig. 2 IIV uptake mapped to the zip code level for black Medicare FFS beneficiaries

Even greater variability in IIV uptake is detected when the data are mapped at the zip code level. In Fig. 1, the percentage of IIV vaccination spans a wide range, from 0.33 to $78.57 \%$. Non-white beneficiaries also exhibited geographic variability, including a distinct nationwide footprint mirroring the concentration of non-white populations in specific regions and a wide range of IIV vaccination percentages at the zip code level (Figs. 2, 3). Zip code IIV percentage uptake can vary significantly between neighboring zip codes, as illustrated in Fig. 2. In the New York city region, areas of high IIV uptake are juxtaposed with some of the lowest in the US (Fig. 4).

\section{DISCUSSION}

Confirming previous analyses, our evaluation documents less than recommended IIV uptake even among a high-risk population-older adults-with insurance coverage. Furthermore, significant disparities were present between white and non-white beneficiaries, those with fewer financial resources, and rural populations. Even in geographic regions with the highest rates of IIV, extremely low rates can be identified in zip codes with large non-white or poor beneficiaries. Although the estimated vaccine rates were somewhat lower, our analysis paralleled trends found in Shen et al. [21], with the lowest rates of influenza immunization found among blacks and Hispanics.

Racial and ethnic disparities were magnified when considering receipt of HD. While white beneficiaries were much more likely to receive $\mathrm{HD}$, all non-white subpopulations, including Asians who enjoy comparable IIV uptake, were much less likely to receive $\mathrm{HD}$ versus $\mathrm{SD}$, as were beneficiaries with a Part D subsidy or residing in a rural region, populations arguably in more need of this more protective intervention. These results comport with well-documented disparities in dissemination of medical innovation reflecting multiple results [22-26]. 


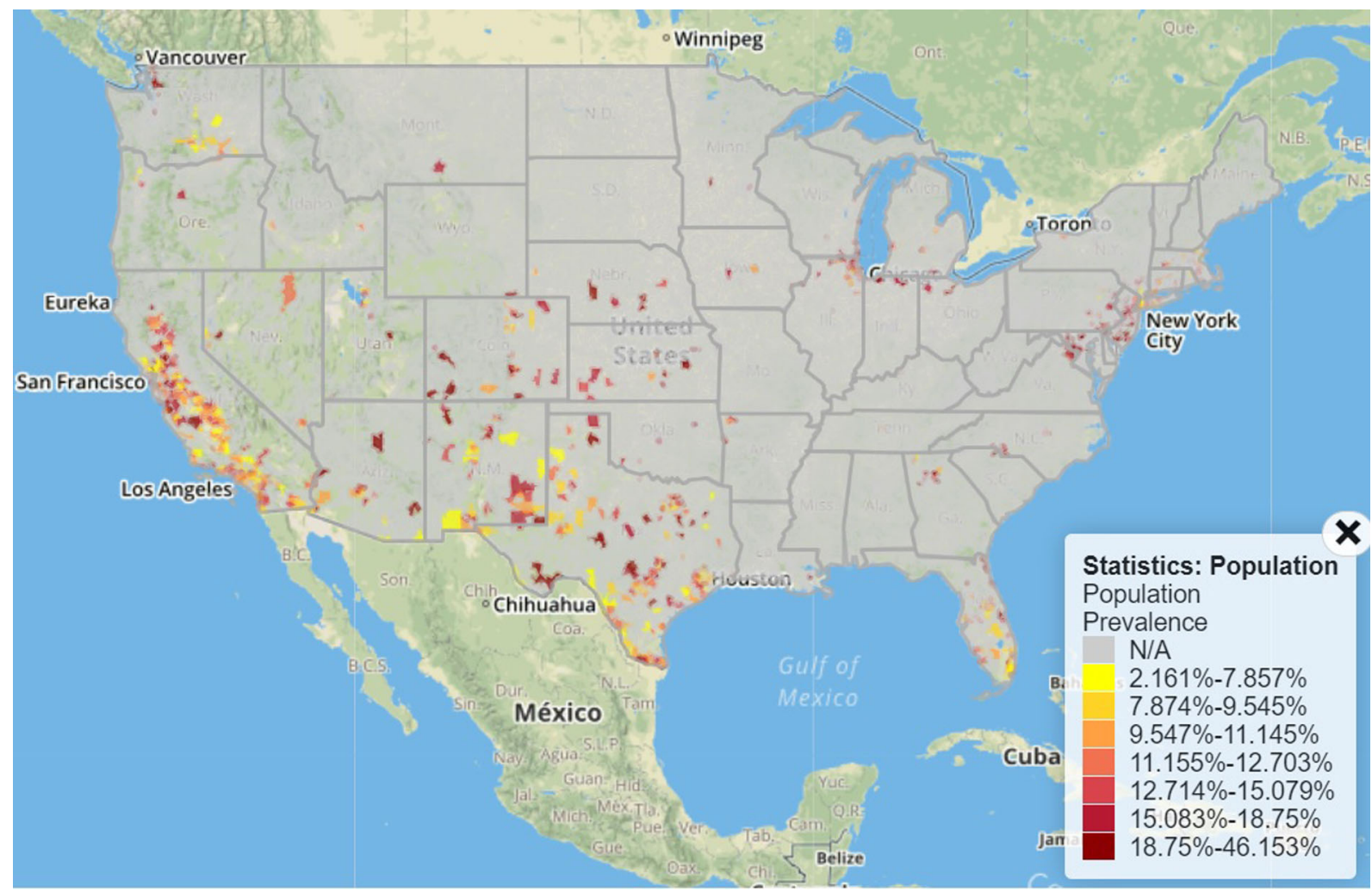

Fig. 3 IIV uptake mapped to the zip code level for Hispanic Medicare FFS beneficiaries

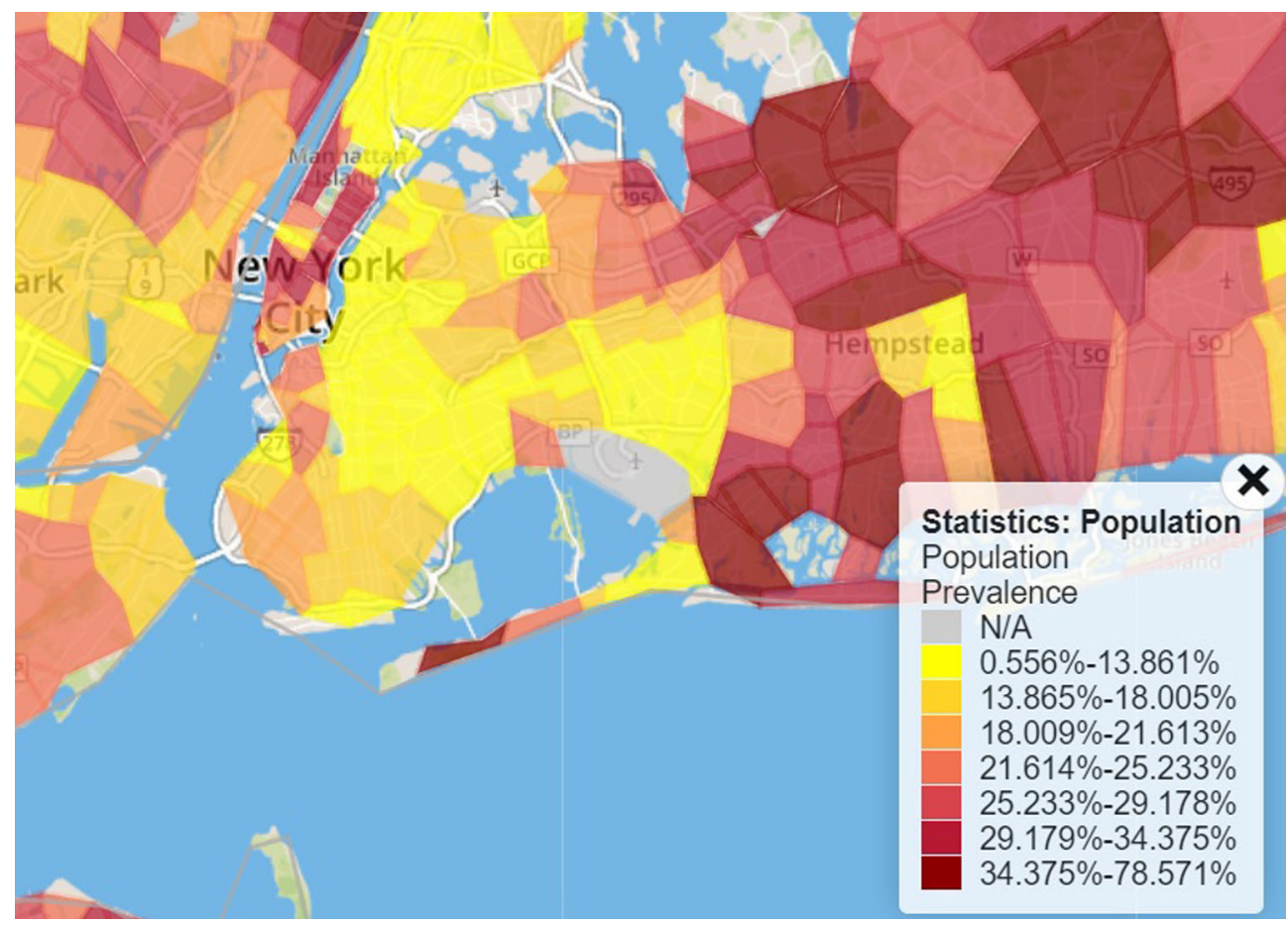

Fig. 4 IIV uptake mapped to the zip code level for New York city region Medicare FFS beneficiaries 
Several factors correlated with higher IIV uptake, including having one or more comorbidities, ambulatory physician visits, or part $\mathrm{D}$ prescriptions, and having received a pneumonia vaccine, as has been previously observed [27]. These trends suggest the positive influence of providers on receiving an influenza vaccine, a finding aligned with the literature showing a provider's strong recommendation has the most positive influence on flu vaccine receipt, including among non-whites [21, 28-30].

This analysis suggests that geographically targeted efforts are required to promote IIV uptake to increase the overall rate of immunization and promote equity [31]. The Center for Medicare and Medicaid Services (CMS) itself has recommended this approach for promoting equity in care and outcomes in Medicare-funded care, increasingly publishing information about geographic disparities, at the state and county level, and staking out a strategy for redress, including quality improvement efforts $[32,33]$

This study has several limitations and suggests several lines of further research. Perhaps the most important limitation is that not all flu vaccines given to Medicare beneficiaries were captured in the Medicare FFS claims data, and this may vary among subpopulations and regions. It is doubtful, however, that a large volume of vaccines is not accounted for. And, as noted in a previous study, the large data set offers an important description of vaccine trends among older adults. Additional studies are necessary and underway to confirm the disparities documented here and better understand the patient, provider, and social contributors to vaccination.

\section{CONCLUSION}

In conclusion, only about half of the senior beneficiaries in the Medicare FFS program in 2015-2016 were shown to have an influenza immunization claim reimbursed. Less than 30\% of black and Hispanic beneficiaries demonstrated this level of influenza immunization reimbursed in Medicare FFS, and only a small fraction of all non-white beneficiaries received
HD, with its added protection for older populations and confirmed economic benefit. Seeing a provider correlated with a higher likelihood of receiving IIV, suggesting a future approach to expand vaccination. GIS visualization of the flu vaccine claims data provides an additional means for precisely targeting efforts geographically, at the zip code level. Urgent and targeted efforts are needed to equitably increase IIV rates, thus protecting the most vulnerable populations from the negative health impact of influenza as well as the tax-paying public from the Medicare costs from failing to do so.

\section{ACKNOWLEDGEMENTS}

Funding. Funding for this study was received from Sanofi Pasteur, Swiftwater, PA. The Rapid Service and Open Access Fees were funded by the authors.

Authorship. All named authors meet the International Committee of Medical Journal Editors (ICMJE) criteria for authorship for this manuscript, take responsibility for the integrity of the work as a whole, and have given final approval for the version to be published.

Disclosures. Liou Xu, Gary A. Puckrein, and Laura Lee Hall are employees of the NMQF. Salaheddin Mahmud, MD, PhD, FRCPC, is an employee of the University of Manitoba. Ed Thommes, PhD, and Ayman Chit, MBiotech, $\mathrm{PhD}$, are employees of Sanofi Pasteur.

Compliance with Ethics Guidelines. This article does not contain any new studies with human or animal subjects performed by any of the authors. The data analyses did not include any patient identifiers, and the aggregated data never included less than 11 patient records as required by NMQF's Data Use Agreement with the Center for Medicare and Medicaid Services as a HIPPA compliant study with a waiver of IRB approval. 
Data Availability. The datasets analyzed during the current study are available from the corresponding author on reasonable request.

Open Access. This article is licensed under a Creative Commons Attribution-NonCommercial 4.0 International License, which permits any non-commercial use, sharing, adaptation, distribution and reproduction in any medium or format, as long as you give appropriate credit to the original author(s) and the source, provide a link to the Creative Commons licence, and indicate if changes were made. The images or other third party material in this article are included in the article's Creative Commons licence, unless indicated otherwise in a credit line to the material. If material is not included in the article's Creative Commons licence and your intended use is not permitted by statutory regulation or exceeds the permitted use, you will need to obtain permission directly from the copyright holder. To view a copy of this licence, visit http://creativecommons.org/licenses/by$\mathrm{nc} / 4.0 /$.

\section{REFERENCES}

1. Roberts AW, Ogunwole SU, Blakeslee L, et al. The population 65 years and older in the United States: 2016 American community survey reports, ACS-38. Washington: US Census Bureau; 2018.

2. Sisko AM, et al. National health expenditure projections, 2018-27: economic and demographic trends drive spending and enrollment growth. Health Aff. 2019;38(3):491-501. https://doi.org/10. 1377/hlthaff.2018.05499 [Health Affairs (Project Hope)].

3. Centers for Disease Control and Prevention. Who is at high risk for flu complications [Internet]. Atlanta (GA). People 65 years and older \& influenza. Available from: https://www.cdc.gov/flu/highrisk/ 65over.htm. Cited 16 Dec 2019.

4. Haq K, McElhaney JE. Immunosenescence: influenza vaccination and the elderly. Curr Opin Immunol. 2014;29:38-42. https://doi.org/10.1016/ j.coi.2014.03.008 (Elsevier BV).

5. Trucchi C, et al. Hospital and economic burden of influenza-like illness and lower respiratory tract infection in adults $\geq 50$ years-old. BMC Health Ser
Res. 2019. https://doi.org/10.1186/s12913-0194412-7 (Springer Science And Business Media LLC).

6. Czaja CA, et al. Age-related differences in hospitalization rates, clinical presentation, and outcomes among older adults hospitalized with influenzaUS influenza hospitalization surveillance network (Flusurv-NET). Open Forum Infect Dis. 2019. https://doi.org/10.1093/ofid/ofz225 (Oxford University Press (OUP), Accessed Dec 16, 2019).

7. Centers for Disease Control and Prevention, National Center for Immunization and Respiratory Diseases (NCIRD) Seasonal influenza (Flu) [Internet]. Atlanta (GA). Estimated influenza illnesses, medical visits, hospitalizations, and deaths In the United States - 2017-2018 influenza season. Available from: https://www.cdc.gov/flu/about/ burden/2017-2018.htm. Cited 16 Dec 2019.

8. McElhaney JE, et al. The unmet need in the elderly: how immunosenescence, CMV infection, co-morbidities and frailty are a challenge for the development of more effective influenza vaccines. Vaccine. 2012;30(12):2060-7. https://doi.org/10.1016/j. vaccine.2012.01.015 (Elsevier BV).

9. Grohskopf LA, et al. Prevention and control of seasonal influenza with vaccines: recommendations of the advisory committee on immunization practices-United States, 2019-2020 Influenza Season. MMWR. 2019;68(3):1-21. https://doi.org/10. 15585/mmwr.rr6803a1 (Centers For Disease Control MMWR Office).

10. DiazGranados CA, et al. Efficacy of high-dose versus standard-dose influenza vaccine in older adults. New Engl J Med. 2014;371(7):635-45. https://doi. org/10.1056/nejmoa1315727 Medical Society).

(Massachusetts

11. Robertson CA, et al. Fluzone ${ }^{\circledR}$ High-dose influenza vaccine. Expert Rev Vacc. 2016;15(12):1495-505. https://doi.org/10.1080/14760584.2016.1254044 (Informa UK Limited).

12. Gravenstein S, et al. Comparative effectiveness of high-dose versus standard-dose influenza vaccination on numbers of US nursing home residents admitted to hospital: a cluster-randomised trial. Lancet Resp Med. 2017;5(9):738-46. https://doi. org/10.1016/s2213-2600(17),30235-7 (Elsevier BV).

13. Lee JKH, et al. Efficacy and effectiveness of highdose versus standard-dose influenza vaccination for older adults: a systematic review and meta-analysis. Expert Rev Vacc. 2018;17(5):435-43. https://doi. org/10.1080/14760584.2018.1471989 (Informa UK Limited). 
14. Wilkinson K, et al. Efficacy and safety of high-dose influenza vaccine in elderly adults: a systematic review and meta-analysis. Vaccine. 2017;35(21): 2775-800. https://doi.org/10.1016/j.vaccine.2017. 03.092 (Elsevier BV).

15. Shireman TI, et al. Cost benefit of high-dose vs standard-dose influenza vaccine in a long-term care population during an A/H1N1-predominant influenza season. J Am Med Direct Assoc. 2019;20(7): 874-8. https://doi.org/10.1016/j.jamda.2018.12. 003 (Elsevier BV, Accessed Dec 16, 2019).

16. Centers for Disease Control and Prevention, National Center for Immunization and Respiratory Diseases (NCIRD). Fluvaxview [Internet]. Atlanta (GA). Flu vaccination coverage, United States, 2018-19 influenza season. Available from: https:// www.cdc.gov/flu/fluvaxview/coverage-

1819estimates.htm. Cited 16 Dec 2019.

17. Lu D, et al. Racial and ethnic disparities in influenza vaccination among adults with chronic medical conditions vary by age in the United States. PLoS ONE. 2017. https://doi.org/10.1371/journal.pone. 0169679.

18. Fiscella $\mathrm{K}$, et al. Impact of influenza vaccination disparities on elderly mortality in the United States. Prevent Med. 2007;45(1):83-7. https://doi.org/10. 1016/j.ypmed.2007.03.007.

19. National Minority Quality Forum. Vaccine Index [Internet]. Washington (DC). Vaccine index. Available from: https://index.nmqf.us/ index?index=vaccine_index\&title=.. Cited 16 Dec 2019.

20. Research Data Assistance Center, Centers for Medicare and Medicaid Services. CMS data files. [Internet]. Baltimore (MD).Master Beneficiary Summary File (MBSF) Base. Available from: https://www. resdac.org/cms-data/files/mbsf-base. Cited 16 Dec 2019.

21. Shen AK, et al. Characteristics of vaccinating providers reported through medicare claims in officebased settings: volume of influenza and pneumococcal vaccinations. Vaccine. 2020;38(1):15-9. https://doi.org/10.1016/j.vaccine.2019.10.029.

22. Patel NJ, et al. Gender, racial, and health insurance differences in the trend of implantable cardioverterdefibrillator (ICD) utilization: a United States experience over the last decade. Clin Cardiol. 2016;39(2):63-71. https://doi.org/10.1002/clc. 22496.

23. Institute of Medicine. Unequal treatment: confronting racial and ethnic disparities in health care. Washington, DC: The National Academies Press; 2003. https://doi.org/10.17226/10260.
24. Piña IL. If it is not health care access or insurance coverage, then why do racial disparities persist? JACC. 2018;6(5):421-3. https://doi.org/10.1016/j. jchf.2018.03.013.

25. Shen AK, et al. Vaccination among medicare-fee-for service beneficiaries: characteristics and predictors of vaccine receipt, 2014-2017. Vaccine. 2019;37(9): 1194-201. https://doi.org/10.1016/j.vaccine.2019. 01.010 .

26. Purnell TS, et al. Achieving health equity: closing the gaps in health care disparities, interventions, and research. Health Aff. 2016;35(8):1410-5. https://doi.org/10.1377/hlthaff.2016.0158.

27. Shen AK, et al. Characteristics of vaccinating providers reported through medicare claims in officebased settings: volume of influenza and pneumococcal vaccinations. Vaccine. 2019;38(1):15-9. https://doi.org/10.1016/j.vaccine.2019.10.029.

28. Poland GA, et al. Effective and equitable influenza vaccine coverage in older and vulnerable adults: the need for evidence-based innovation and transformation. Vaccine. 2019;37(16):2167-70. https://doi. org/10.1016/j.vaccine.2019.02.076.

29. Quinn SC. African American adults and seasonal influenza vaccination: changing our approach can move the needle. Hum Vaccin Immunother. 2018;14(3):719-23. https://doi.org/10.1080/ 21645515.2017.1376152.

30. Shen AK, et al. Patient characteristics of medicare beneficiaries who report not getting influenza and pneumococcal vaccinations, 2001-2013". Hum Vaccin Immunother. 2019. https://doi.org/10. 1080/21645515.2019.1688033.

31. Fiscella K, Sanders MR. Racial and ethnic disparities in the quality of health care. Ann Rev Public Health. 2016;37(1):375-94. https://doi.org/10. 1146/annurev-publhealth-032315-021439.

32. Centers for Medicare and Medicaid Services. CMS Center for Minority Health. [Internet]. Baltimore (MD). Mapping Medicare disparities. Available from: https://www.cms.gov/About-CMS/AgencyInformation/OMH/OMH-Mapping-MedicareDisparities. Cited 16 Dec 2019.

33. Centers for Medicare and Medicaid Services. Office of Minority Health. [Internet]. Baltimore (MD). The CMS equity plan for improving quality in Medicare. Available from: https://www.cms.gov/About-CMS/ Agency-Information/OMH/OMH_Dwnld-CMS_ EquityPlanforMedicare_090615.pdf. Cited 16 Dec 2019. 